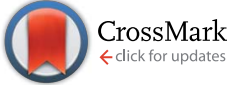

Cite this: RSC Adv., 2015, 5, 87589

Received 4th September 2015 Accepted 9th October 2015

DOI: $10.1039 / c 5 r a 18024 d$

www.rsc.org/advances

\section{Excellent impact strength of ethylene-methyl acrylate copolymer toughened polycarbonate $\dagger$}

\begin{abstract}
Nisha Bagotia, ${ }^{a}$ Bhanu Pratap Singh, ${ }^{b}$ Veena Choudhary ${ }^{\star c}$ and D. K. Sharma ${ }^{a}$
The intrinsic notch sensitivity of polycarbonate (PC) demands improvement in the notched impact strength for a variety of applications. Blends of PC/ethylene-methyl acrylate (EMA) copolymer of different compositions were prepared by melt blending using a co-rotating twin-screw extruder. The notched izod impact strength of PC/EMA blends showed a positive blending effect and increased $381 \%$ with incorporation of a very little amount of EMA (5\%) with a marginal decrease in the tensile strength of PC. Tensile data was also analyzed by using predictive theories. Incorporation of EMA decreases the glass transition temperature of PC and facilitates its processing. Scanning electron micrographs of cryogenically fractured samples after etching were used to study the phase structure. A two phase morphology was seen with a fine dispersion of rubber granules in the PC matrix. On the other hand, the impact fractured surface of PC/EMA blends indicated debonding of EMA particles, leaving hemispherical bumps, indicating inadequate interfacial adhesion between $P C$ and EMA.
\end{abstract}

\section{Introduction}

Polycarbonate (PC) is a widely used applied engineering thermoplastic ${ }^{\mathbf{1 , 2}}$ because it possesses several distinct properties such as transparency, dimensional stability, ${ }^{3,4}$ flame retardance, high heat distortion temperature, high mechanical strength over a wide range of temperature scale ${ }^{5,6}$ and high dart impact strength. ${ }^{7-11}$ Applications of PC in blends with other polymers are frequently impeded by a high processing temperature, at which other components may undergo thermal degradation. ${ }^{12}$ However, PC is known to exhibit poor solvent resistance, poor processability and notch sensitivity. ${ }^{13}$ Though PC exhibits tough behavior in stress-strain (tensile test) and in unnotched impact tests, ${ }^{\mathbf{1 4}}$ the toughness is not retained when the specimen is thick and the notch is sharp..$^{15,16}$ It has a very high degree of notch sensitivity, which leads to a catastrophic decrease in impact strength in a notched specimen. ${ }^{17}$ The notch sensitivity of PC is due to the change in stress state at the notch from plane stress to plane strain and the resulting change in failure mechanism from shearing to crazing. ${ }^{18}$ The deficiency can be alleviated by means of covering PC surface with a protective polymer, ${ }^{19}$ which is rather impractical. One method, which has been successful in toughening notch-sensitive polymers such as PC, is rubber

${ }^{a}$ Centre for Energy Studies, Indian Institute of Technology Delhi, New Delhi 110016, India. E-mail: veenach@hotmail.com; Tel: +91-11-26591423

${ }^{b}$ Physics and Engineering of Carbon, CSIR-National Physical Laboratory, New Delhi 110012, India

${ }^{c}$ Centre for Polymer Science and Engineering, Indian Institute of Technology Delhi, New Delhi 110016, India

$\dagger$ Electronic supplementary information (ESI) available. See DOI: $10.1039 / \mathrm{c} 5 \mathrm{ra} 18024 \mathrm{~d}$ toughening. ${ }^{\text {,20-23 }}$ However, these problems can be partly solved by blending PC with a miscible elastomer, decreasing the glass transition temperature and processing temperature. Several studies have been carried out to develop effective toughening methods to improve the impact strength, processability and solvent resistance of PC. ${ }^{24-30}$ Of the many PC and elastomer blends studied so far, only a few have become technologically feasible and commercially viable because of ease of processing, higher thermal stability and low cost. Most of the blends in multicomponent polymer systems are incompatible for a variety of reasons such as the absence of any specific interaction between their blend constituents, dissimilarity in their structures, broad difference in their viscosities, surface energy, or activation energy of flow and polarity. Toughening of PC has been studied by using acrylonitrile-butadiene-styrene (ABS), ${ }^{31}$ polyethylene (PE), ${ }^{32}$ poly(ethylene terephthalate) $(\mathrm{PET})^{33,34}$ etc.

Ramteke et al. studied mechanical properties of PC/modified acrylonitrile-styrene-acrylate (MASA) terpolymer blends. ${ }^{35}$ They observed that the highest izod impact strength of PC/MASA blends almost 1.1 times of neat PC (110\% increase) found at $10 \mathrm{wt} \%$ of MASA. Tensile strength of different compositions of PC/MASA blends decreased with increase in MASA content. Kumar et al. worked on PC/poly(dimethyl siloxane) (PDMS) rubber blend. The notched izod impact strength of PC/PDMS blend increased significantly approximate 3.72 times of neat PC when the rubber content was $20 \%$ wt or volume. Both, tensile strength and modulus decreased by 1.2 times of neat PC (58.9 to $49.1 \mathrm{MPa}$ ) and 1.18 times of neat PC (838.3 to 709.7 $\mathrm{MPa}$ ) respectively at $20 \%$ wt or volume content of PDMS. ${ }^{36}$ Zhang et al. studied the effect of hydroxyl content and viscosity of the hydroxyl-terminated PDMS (PDMS-OH) on the 
toughening of PC. They used PDMS-OH of four different viscosity $\left(750,5000,20000\right.$ and $\left.80000 \mathrm{~mm}^{2} \mathrm{~s}^{-1}\right)$ and PDMS as reference (500 $\mathrm{mm}^{2} \mathrm{~s}^{-1}$ ) for this study. In PC/PDMS-OH-80 000 blend, the highest toughness point of these blends observed by adding $1 \mathrm{wt} \%$ PDMS-OH-80 000 in PC. The impact toughness of PC/PDMS-OH-80 000-1\% was $73.8 \mathrm{~kJ} \mathrm{~m}^{-2}$, which was $62 \%$ higher than that of pure PC whose impact toughness was $45.5 \mathrm{~kJ}$ $\mathrm{m}^{-2}$. The highest toughness observed when the contents of PDMS-OHs was $0.125 \mathrm{wt} \%, 0.25 \mathrm{wt} \%$, and $0.5 \mathrm{wt} \%$ for $\mathrm{PC} /$ PDMS-OH-750, PC/PDMS-OH-5000 and PC/PDMS-OH-20 000 blends. The impact toughness of PC/PDMS-OH-750-0.125\%, PC/PDMS-OH-5000-0.25\% and PC/PDMS-OH-20 000-0.5\% was $49 \%, 45 \%$ and $58 \%$ higher than that of neat PC. The addition of PDMS-OH on one hand, improved the tensile strength and yield strength of PC, but on the other hand, deteriorated the modulus of PC. ${ }^{37}$ Ramesh et al. carried out work on the recovery and recycling of plastics waste, primarily $\mathrm{PC}, \mathrm{ABS}$ and high impact polystyrene (HIPS), from end-of-life waste electrical and electronic equipments. Virgin PC (VPC) and impact modifier (IM) (ethylene-acrylic ester-glycidyl methacrylate) also used for further study. The impact strength increased 169\% higher than the recycled blended plastic (RBP) by adding $10 \% \mathrm{IM}$ in RBP and $10 \%$ VPC blend. The tensile strength and modulus was not much affected.$^{38}$ Farzadfar et al. investigated the effect of reactive compatiblizer (ABS- $g$-(maleic anhydride) (ABS- $g$-MA) and (ethylene-vinyl acetate)- $g$-(maleic anhydride) (EVA- $g$-MA)) on the mechanical and morphological properties of recycled PC/ ABS blends. The highest notched impact strength observed almost 106\% higher than that of the recycled PC and tensile strength decreased by $4.26 \%$ when content of ABS- $g$-MA was 5 phr $(4.76 \%)$. The notched impact strength increased by $253 \%$ than that of recycled PC and tensile strength decreased by $12.2 \%$ when content of EVA- $g$-MA was 5 phr. The impact strength increased by $42.8 \%$ than that of neat PC and tensile strength decreased by $18 \%$ than that of neat PC at $10 \mathrm{phr}$ (9.09\%) of EVA- $g$-MA. ${ }^{39}$

In the present study, blending of PC with an ethylene-methyl acrylate (EMA) elastomer was carried out for the first time to investigate its effect on the mechanical, morphological and thermal behavior of PC. The notched izod impact strength improved significantly $(\sim 381 \%)$ at a very low loading of EMA without affecting other important mechanical properties.

\section{Experimental}

\section{Materials}

Commercial grade of polycarbonate (PC) LEXANTM Resin 143 used in the present study was obtained from SABIC Innovative Plastics (MFI-10.5 g/10 min at $300{ }^{\circ} \mathrm{C}$ with $1.2 \mathrm{~kg}$, density-1.19 g $\mathrm{cm}^{-3}$ ). Ethylene-methyl acrylate (EMA) copolymer, which was blended with PC, was a product of DuPont Packaging \& Industrial Polymers under trade name Elvaloy® AC 1330 (MFI-3 g $\mathrm{min}^{-1}$ at $190{ }^{\circ} \mathrm{C}$ and $2.16 \mathrm{~kg}$, density- $0.95 \mathrm{~g} \mathrm{~cm}^{-3}$ ) [Table $\mathrm{S} 1$ see ESI $\dagger$. EMA is a copolymer of ethylene (70\% by weight) and methyl acrylate ( $30 \%$ by weight) and the chemical structure is given below.

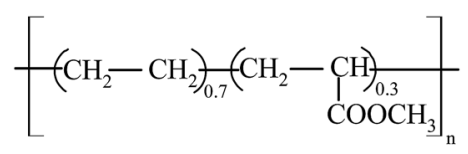

Chemical Structure of EMA

\section{Preparation of blends}

PC/EMA blends were prepared by mixing PC with varying amounts of EMA varying from $0-30 \%$. Required amount of polymer granules were mixed in a high speed mixer, followed by melt blending using co-rotating twin-screw extruder (Lab Tech Engineering Company Ltd.) as shown in Fig. 1. Prior to extrusion, PC and EMA was dried in vacuum oven for 8-10 h at a temperature of $80{ }^{\circ} \mathrm{C}$. The temperature in the extruder ranged from 140 to $270{ }^{\circ} \mathrm{C}$ in the zones I to IX and in die zone. Melt compounding was done at a screw speed of $150 \mathrm{rpm}$. The extruded strands of the blends were quenched in cold water, granulated and the granules were dried before further processing. The unblended PC was also subjected to identical

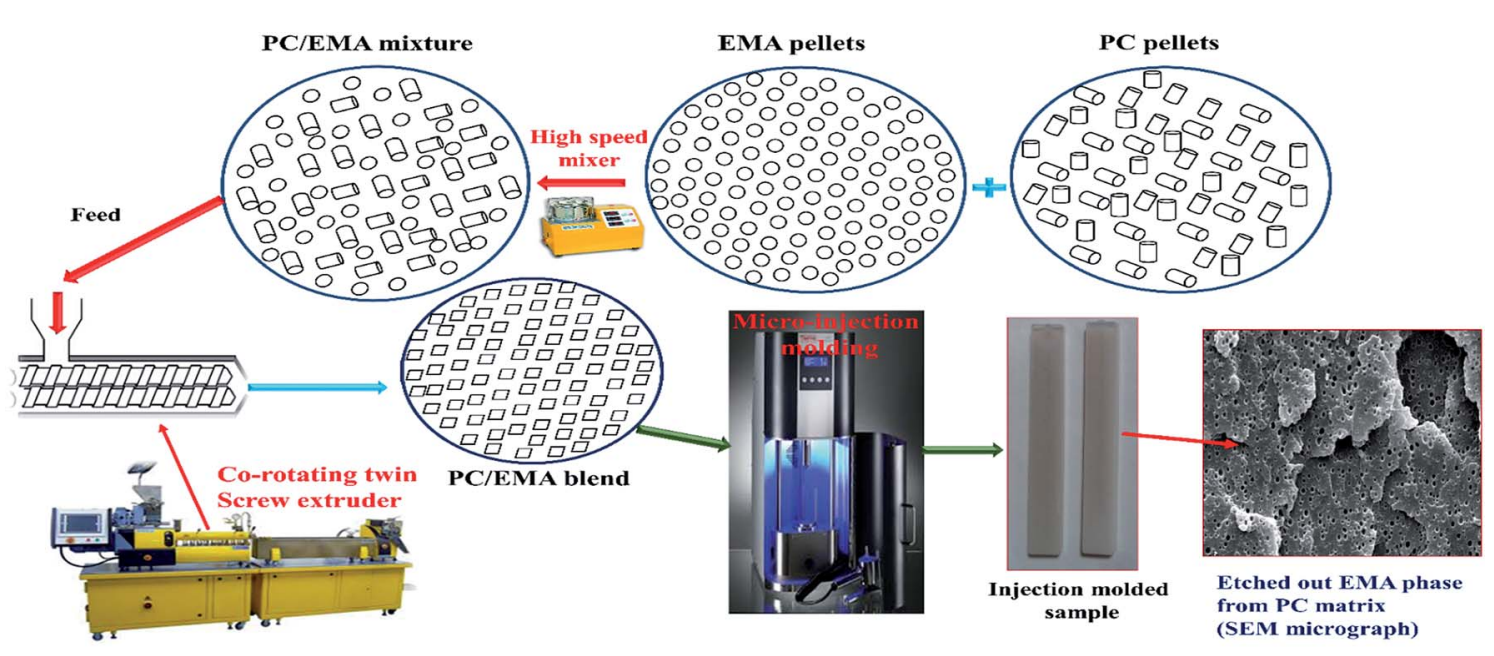

Fig. 1 Schematic diagram of processing of PC/EMA blends. 
extrusion process to ensure the same thermal history as the blends. The PC/EMA blends were prepared by varying the content of EMA from 1 to $30 \%$ in neat PC matrix. The details of blend formulation, sample designation and temperature profile used for blending are given in ESI (Tables S2 and $\mathrm{S} 3 \dagger$ ).

\section{Measurements}

\section{Mechanical properties}

To determine tensile and impact properties, the test samples were prepared by using micro-injection molding machine (Thermo Scientific HAAKE Mini Jet II). The following conditions were used:

Cylinder temperature- $250{ }^{\circ} \mathrm{C}$.

Mold temperature- $100{ }^{\circ} \mathrm{C}$.

Pressure-640 bar.

Tensile testing was done using dumbbell shaped injection molded specimen on a Zwick Z010 universal testing machine according to ASTM D-638, cross head speed was $10 \mathrm{~mm} \mathrm{~min}^{-1}$ and gauge length was $15 \mathrm{~mm}$. Izod impact strength of notched samples was measured on low energy impact tester (Tinius Olsen) according to ASTM D256. All testings were done at room temperature and the notch of $0.2 \mathrm{~cm}$ width was made by using notch cutter. At least five samples were tested for each composition and average values are reported.

\section{Morphological studies}

The scanning electron microscopy (SEM) was used to investigate the state of dispersion of rubber particles in PC matrix. For morphological analysis, cryogenically fractured tensile specimens etched by hexane to remove EMA were used. The samples were coated with gold prior to scanning. The SEM micrographs were recorded on scanning electron microscope (Zeiss EVO 50).
The acceleration voltage used was $20 \mathrm{kV}$ and the magnification was 10000 .

\section{Thermal studies}

The thermal stability of neat PC, EMA and PC/EMA blends was studied using TA thermogravimetric analyser (TGA) (Q-50). The sample was heated in nitrogen atmosphere (flow rate $50 \mathrm{~cm}^{3}$ $\min ^{-1}$ ) from room temperature to $800{ }^{\circ} \mathrm{C}$ at a heating rate of $20{ }^{\circ} \mathrm{C} \min ^{-1}$ and a sample weight of 5-6 $\mathrm{mg}$ was used for recording thermogravimetry/derivative thermogravimetry (TG/ DTG) traces. The degradation temperatures of the samples at various stages were calculated from the TG/DTG traces.

The glass transition temperature $\left(T_{\mathrm{g}}\right)$ of neat PC, EMA and PC/EMA blends was determined through differential scanning calorimetry (DSC) (Q200 V23.10 Build 79) analysis under nitrogen atmosphere (flow rate $50 \mathrm{~cm}^{3} \mathrm{~min}^{-1}$ ) and a sample weight of 5-6 $\mathrm{mg}$ was used for recording DSC scans. The samples were heated from room temperature to $200{ }^{\circ} \mathrm{C}$, kept at $200{ }^{\circ} \mathrm{C}$ for $3 \mathrm{~min}$ for removing the thermal history and then cooled to room temperature. The samples were reheated to 200 ${ }^{\circ} \mathrm{C}$ and the second heating scans were taken for determination of $T_{\mathrm{g}}$. The heating and cooling rate of the samples during DSC analysis was $10{ }^{\circ} \mathrm{C} \min ^{-1}$.

\section{Results and discussion}

\section{Mechanical properties}

Impact property. The izod impact strength of PC/EMA blends with increasing EMA content is shown in Fig. 2a and detailed results are provided in Table S4 (see ESI $\dagger$ ). The sharp notch causes a catastrophic reduction of impact strength of pure PC. ${ }^{\mathbf{4 0}}$ However it is observed that 3 and $5 \mathrm{wt} \%$ of EMA copolymer leads to a drastic increase in izod impact strength of PC/EMA blends
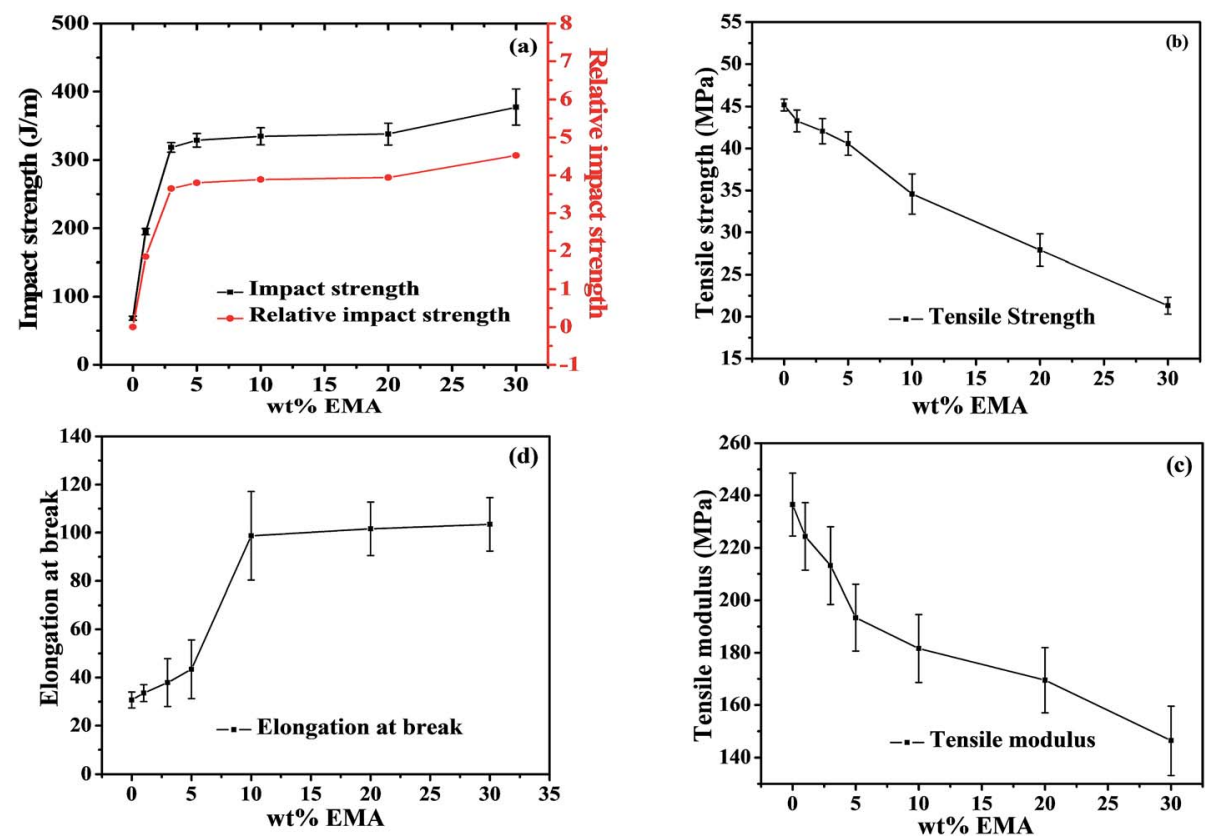

Fig. 2 Plot of (a) impact strength and relative impact strength (b) tensile strength (c) tensile modulus (d) elongation at break versus wt\% of EMA. 
(significant toughening of PC). Higher loading ( $>5 \%)$ of EMA in PC/EMA blends did not show any significant effect on the impact strength. Significant increase in impact strength almost $381 \%$ (4.81 times of neat PC) is observed at $5 \mathrm{wt} \%$ of EMA content. The relative izod impact strength of PC/EMA blends are plotted against wt\% of EMA as shown in Fig. 2a. The incorporation of only 1 and 3 wt $\%$ EMA in PC shows almost $184 \%$ and $366 \%$ (2.85 and 4.65 times of neat PC) increment in izod impact strength respectively. The value increases $389-452 \%$ (4.89-5.52 times) with increase in EMA content i.e. from $10-30 \mathrm{wt} \%$ as compared to that of PC. Thus, the elastomer EMA substantially toughens the PC.

Tensile property. The plots of tensile strength, tensile modulus and elongation at break for PC/EMA blends in the absence and presence of varying amounts of EMA are shown in Fig. 2b-d respectively and the results are summarized in Table S4 (see ESI $\dagger$ ). It can be seen from Fig. $2 \mathrm{~b}$ and c, that the tensile strength and tensile modulus of PC/EMA blends decrease with incorporation of EMA. Decrease in tensile strength [stress at peak, Fig. $2 \mathrm{~b}$ ] is negligible at $1 \mathrm{wt} \%$ EMA level. Tensile strength decreased by $6 \%$ and $10 \%$ at EMA content of $3 \mathrm{wt} \%$ and $5 \mathrm{wt} \%$ respectively. Tensile strength decreased by $24-53 \%$ with increase in EMA content from 10 to $30 \mathrm{wt} \%$, depending on the blend composition. Tensile modulus of PC/EMA blends decreased by $5 \%, 9 \%$ and $18 \%$ with increase in content of EMA $1 \mathrm{wt} \%, 3 \mathrm{wt} \%$ and $5 \mathrm{wt} \%$ respectively. In similar way, the decrease in tensile modulus is $23-38 \%$ as the EMA content increased from 10 to $30 \%$ (Fig. 2c). The elongation at break increases from $10 \%$ to $243 \%$ with increase in content of EMA from 1 to $30 \%$ as shown in Fig. 2 d. The lowering of tensile strength in PC/EMA blends may be due to the presence of rubbery EMA particles acting as stress concentrators which result in yielding at an overall stress lower than that for neat PC. The decrease in tensile modulus of PC when blending with EMA may be accounted by the softening effect of EMA copolymer. From these results, it can be concluded that addition of ethylene-methyl acrylate in PC matrix decreases its tensile strength and modulus value but compared to enhancement in the impact strength this decrease in tensile strength and tensile modulus is quiet low. Fig. 3 shows the comparison of mechanical properties such as tensile strength and impact strength upon incorporation of EMA in PC matrix with other elastomers.

In PC/EMA blends, only 5 wt\% of EMA incorporation in PC matrix shows drastic increase in notched impact strength i.e. $\sim 381 \%$ and decrease in tensile strength (10\%) is very small in comparison to the increment in notched impact strength. Kumar et al. reported $272 \%$ increment in notched impact strength and $16 \%$ decrease in tensile strength with $10 \mathrm{wt} \%$ of PDMS in PC/PDMS. Ramteke et al. reported $110 \%$ increase in notched impact strength and $7 \%$ decrease in tensile strength at $10 \mathrm{wt} \%$ of modified acrylonitrile-styrene-acrylate (MASA) in PC matrix. Farzadfar et al. investigated that $9 \mathrm{wt} \%$ of EVA- $g$-MA in $\mathrm{PC} / \mathrm{ABS}$ blend increases the notched impact strength by $79 \%$ and tensile strength decreases by $12.74 \%$. Liu et al. studied that $13 \mathrm{wt} \%$ of SMA in PC/ABS blend shows $36 \%$ increase in izod impact strength and $15 \%$ decrease in tensile strength.

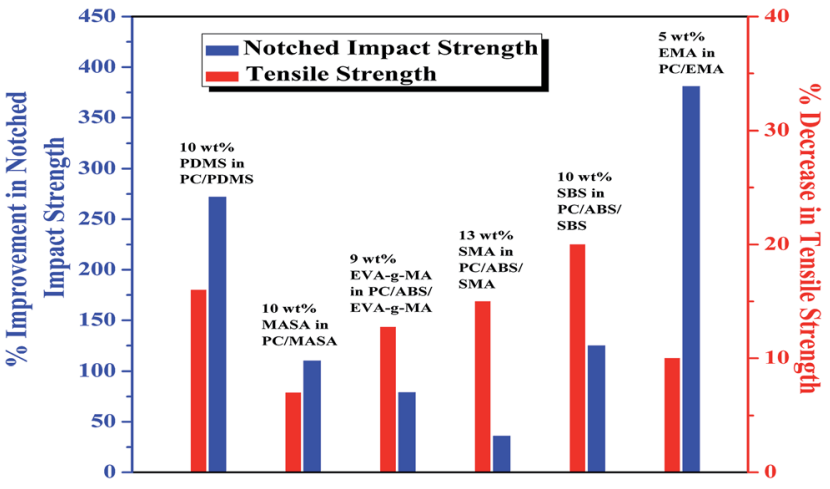

Fig. 3 Comparison of notched impact strength and tensile strength of PC/EMA blend with other PC blends [PDMS-polydimethylsiloxane, MASA-modified acrylonitrile-styrene-acrylate, EVA-g-MA (ethylenevinyl acetate)- $g$-(maleic anhydride), SMA-styrene-maleic anhydride, SBS-styrene-butadiene-styrene block]. . $^{35,36,39,41,42}$

Taşdemir et al. reported that $10 \mathrm{wt} \%$ of SBS in PC/ABS blend shows $125 \%$ increase in izod impact strength and 20\% decrease in tensile strength. These comparative results show that in PC blended with EMA has highest improvement in the impact strength with lowest deterioration in tensile strength. Therefore, we can say that EMA is the most effective toughening agent for PC.

SEM characterization of PC/EMA blends. This section deals with the morphological studies carried out on the PC/EMA blends with EMA level varying from 0 to $30 \mathrm{wt} \%$. Fig. $4 \mathrm{a}-\mathrm{g}$ shows the scanning electron micrographs of the cryogenically fractured etched surface of PC and PC/EMA rubber blends. The SEM analysis of these blends show two different types of morphology. A spherical dispersed morphology was observed in blends having EMA content ranging from 1 to $20 \mathrm{wt} \%$, as seen in Fig. $4 \mathrm{~b}-\mathrm{f}$. The number and size of spherical dispersed domains increases with increase of EMA content (1 to $20 \mathrm{wt} \%$ ) in PC matrix [Table. S5 see ESI†]. On the other side, a longitudinal morphology was observed at an EMA loading of $30 \mathrm{wt} \%$ (Fig. 4g). The enhancement of dispersed phase size may be due to the coalescence of rubber droplets at higher EMA loading, the elongated shape arises from the elongational flow of the softer rubber (EMA) component in the rigid plastic (PC) phase during the injection molding of samples.

Fracture surface analysis. SEM photomicrographs of notched impact fractured surface of the PC/EMA blends are presented in Fig. 5. Neat PC exhibits brittle fracture while PC/ EMA blends show debonding of EMA particles with hemispherical bumps, indicating adhesion between PC and EMA and morphology did not change upto an EMA level of $20 \mathrm{wt} \%$ [Fig. 5a-f]. The size of hemispherical bumps increases with increase of EMA content in PC matrix from 1 to $20 \mathrm{wt} \%$ [Fig. 5be]. The impact fractured topology of the PC/EMA blends at an EMA level higher than $20 \mathrm{wt} \%$ show a different perspective, indicating elongated particles protruding from the surface or lump of debonded EMA along with some spherical debonded EMA particles. This behavior may be due to the co-continuous nature of the dispersed phase in these blends. This kind of 

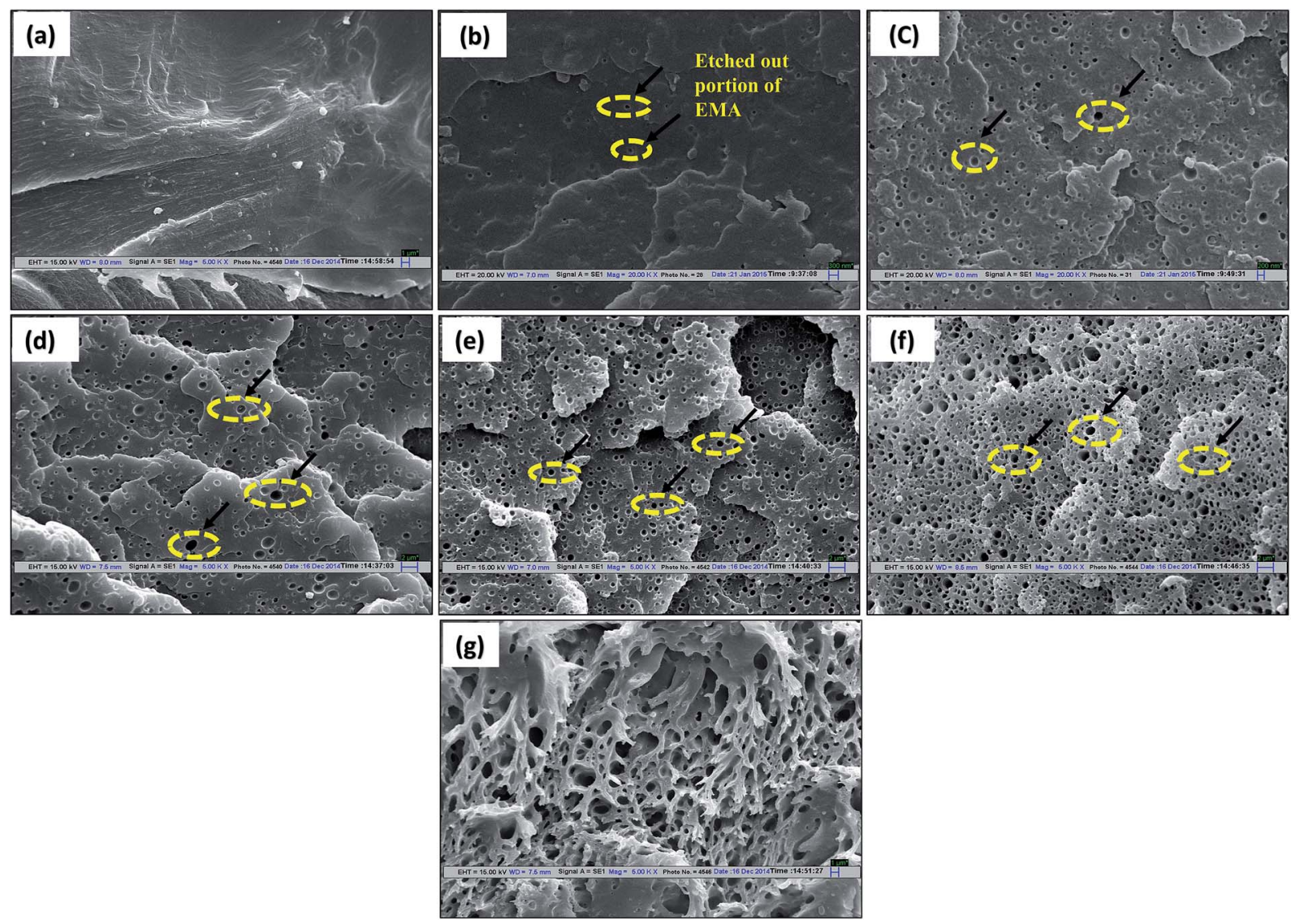

Fig. 4 (a-g): SEM photomicrographs of cryogenically fractured etched surface of: (a) PC; (b) PCE1; (c) PCE3; (d) PCE5; (e) PCE10; (f) PCE20; (g) PCE30 (yellow dashed circles represents etched out portion of EMA rubber).

morphological observation was also seen in PC/HDPE blends, suggesting a brittle, low-energy fracture. ${ }^{43}$ The deformation pattern changed considerably as EMA content in PC/EMA blends was more than $20 \mathrm{wt} \%$ and is characterized by brittle fracture. There is a little sign of plastic deformation or cavitation of the EMA particles.

Toughening of plastics by incorporation of rubber is well documented in the literature. ${ }^{44,45}$ Toughening is mainly either due to crazing or shear yielding. From morphological characterization we can conclude that toughening of PC is due to the cavitation of the rubber particles (crazing). Cavitation of the dispersed rubber phase relieves the plain strain constraint which then allows the matrix between the particles to undergo shear yielding.

\section{Theoretical analysis of tensile strength (stress at peak)}

In order to assess the level of interfacial adhesion in polymer blends and composites, the following models were used. These models have been used previously to analyze blends of $\mathrm{PC} / \mathrm{high}-$ density polyethylene (HDPE), PC/polystyrene, polyamide 6/ ethylene-vinyl acetate (EVA) and several other composites. ${ }^{46-49}$ Three models used to analyze the tensile strength results obtained in this study are as follows:

Model 1: Neilsen's first power-law model: ${ }^{50}$

$$
\sigma_{\mathrm{b}} / \sigma_{\mathrm{m}}=\left(1-\phi_{1}\right) S
$$

Model 2: Neilsen's two-third power-law model::50

$$
\sigma_{\mathrm{b}} / \sigma_{\mathrm{m}}=\left(1-\phi_{1}{ }^{2 / 3}\right) S^{\prime}
$$

Model 3: Nicolais and Narkis model: ${ }^{51}$

$$
\sigma_{\mathrm{b}} / \sigma_{\mathrm{m}}=\left(1-K_{\mathrm{b}} \phi_{1}^{2 / 3}\right)
$$

Where $\sigma_{\mathrm{b}}$ and $\sigma_{\mathrm{m}}$ represent the tensile strength of blend and PC matrix respectively and $\phi_{1}$ the volume fraction of EMA in blends. $S$ and $S^{\prime}$ in eqn (1) and (2) are the Neilsen parameters in first and two third power law models respectively. The maximum value of $S$ and $S^{\prime}$ is unity for no stress concentration effect. In the third model, $K_{\mathrm{b}}$ in eqn (3) is an adhesion parameter; the maximum value of $K_{\mathrm{b}}$ is 1.21 for spherical inclusion of the minor phase having no adhesion. ${ }^{51}$ The three models [eqn (1)-(3)] were employed to analyze the tensile strength results in order to evaluate interfacial adhesion, if any, by comparing the experimental values with those predicted by the models. The values of $S, S^{\prime}$ and $K_{\mathrm{b}}$ are listed in Table S6 (see ESI $\dagger$ ), giving a comparison between the experimental data and theoretical models. Plots of relative tensile strength $\left(\sigma_{\mathrm{b}} / \sigma_{\mathrm{m}}\right)$ versus $\phi_{1}$ of blends predicted using these models are presented in Fig. 6a-c. 

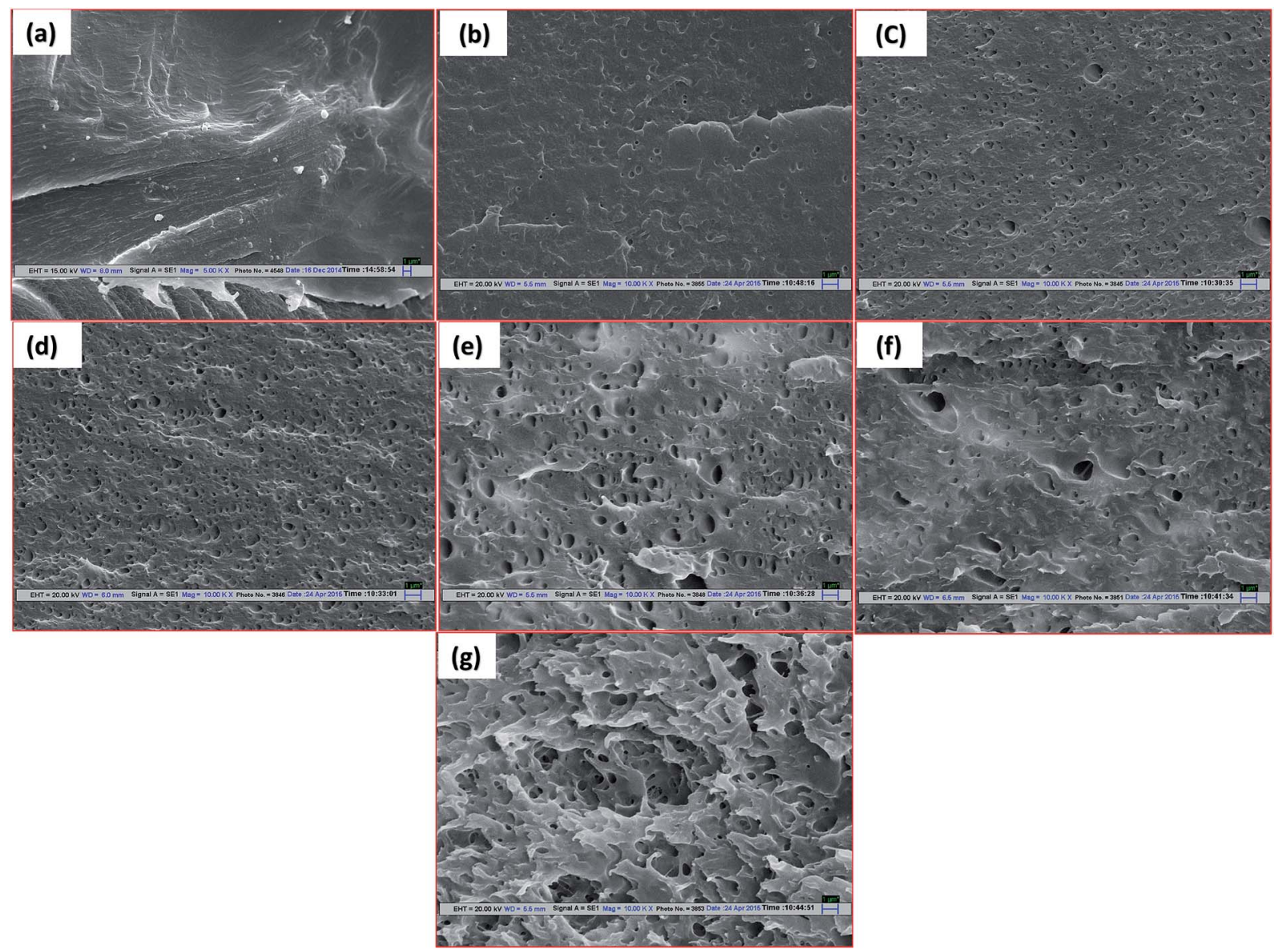

Fig. 5 (a-g): SEM photomicrographs of impact fractured surface of: (a) PC; (b) PCE1; (c) PCE3; (d) PCE5; (e) PCE10; (f) PCE20; (g) PCE30.

In Fig. 6a, values of relative tensile strength $\left(\sigma_{\mathrm{b}} / \sigma_{\mathrm{m}}\right)$ predicted from Neilsen's first power-law model with $S=1, S=0.878$, and experimental results are plotted as a function of $\phi_{1}$. The line with $S=1$ represents perfect adhesion. The experimental values are closer to those predicted from the above equations with $S=$ 1 up to $\phi_{1}=0.06$ (5 wt\%) and higher than the line when $S=$ 0.878 . For samples having range from $\phi_{1}=0.11-0.24(10-20$ wt\%), the experimental values were closer to the line with $S=$ 0.878 . For samples having higher EMA content ( $30 \mathrm{wt} \%$ ), the $\sigma_{\mathrm{b}} /$ $\sigma_{\mathrm{m}}$ value deviate and lower than the predicted curves. It seems, therefore, that blends having EMA content 1-5 wt\%, exhibited good adhesion. This shows that at an EMA loading higher than $\phi_{1}=0.06(5 \mathrm{wt} \%)$, the blends cannot take excessive stress since the interfacial adhesion is lowered.

In Fig. $6 \mathrm{~b}$, the relative tensile strength values $\left(\sigma_{\mathrm{b}} / \sigma_{\mathrm{m}}\right)$ predicted from Neilsen's two-third power-law model with $S^{\prime}=1, S^{\prime}$ $=1.02$ and experimental results are plotted versus $\phi$. There is a good agreement between experimental and theoretical values predicted using Neilsen's two-third power-law model with $S^{\prime}=$ $1, S^{\prime}=1.02$ over the whole composition range. On the other hand, experimental values agree well with the predicted values (with $S=1$ ) using Neilsen's first power-law model upto $\phi_{1}=0.06$ (5 wt\%) whereas it deviates from the predicted values (with $S=1$ and $S=0.878$ ) for samples with $\phi_{1}>0.06$. So from these results it can be concluded that Neilsen's two-third power-law model is more suitable than first power-law model over the whole composition range which is based on the no adhesion, which is not supported by morphological and DSC results. Adhesion of rubber with PC matrix and its compatibility has been supported by morphological characterization and DSC studies. DSC studies showed a decrease in $T_{\mathrm{g}}$ upon incorporation of EMA and there is a good agreement between calculated (Fox equation) and experimental $T_{\mathrm{g}}$ values (Table 1) upto EMA content $\phi_{1}=$ 0.06 ( $5 \mathrm{wt} \%)$. On the basis of these results we can say that first power law model is more suitable than other models.

The third model has a weightage factor $K_{\mathrm{b}}$ that represents the dispersed phase as spherical inclusions. When there is no adhesion of the inclusions to the matrix, $K_{\mathrm{b}}=1.21$. The analysis shows an average value of $K_{\mathrm{b}}=0.893$, which is less than 1.21. In Fig. $6 \mathrm{c}$, the relative tensile strength values predicted from model 3 with $K_{\mathrm{b}}=1.21, K_{\mathrm{b}}=0.893$ and the experimental results are plotted as a function of volume fraction of EMA $\left(\phi_{1}\right)$. Beyond $\phi_{1}$ $=0.24(20 \mathrm{wt} \%)$, the data deviate from the model with $K_{\mathrm{b}}=$ 0.893 and lie closer to the line with $K_{\mathrm{b}}=1.21$. This indicates the reduction of interphase interaction, probably due to the coalescence and sequential larger domain formation of the EMA phase as supported by the morphological characterization. This is also supported by the DSC scan where we fixed change in $T_{\mathrm{g}}$ 

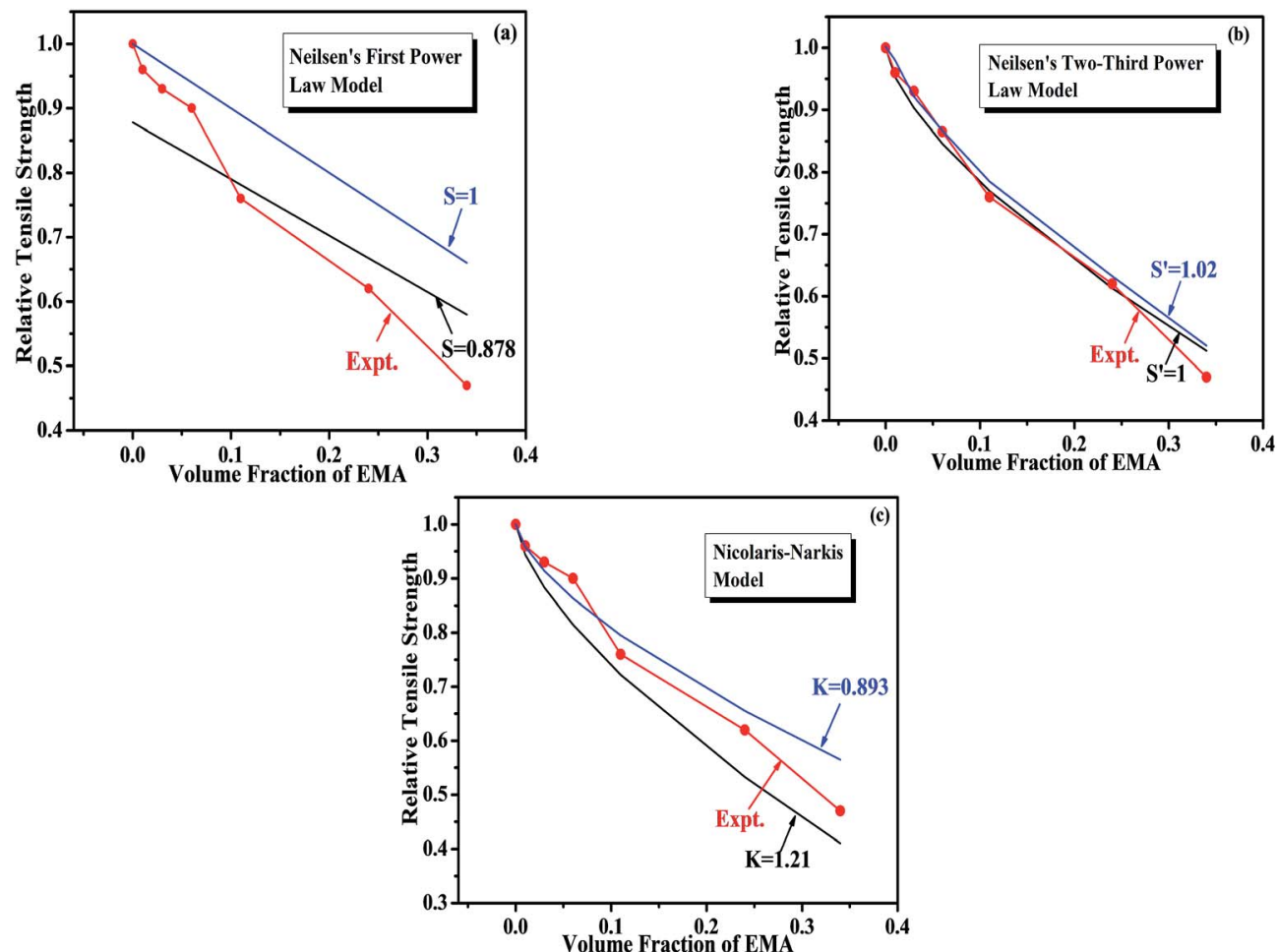

Fig. 6 Plot of relative tensile strength versus volume fraction of EMA experimental results and predicted from (a) Neilsen's first power-law model (b) Neilsen's two-third power-law model (c) Nicolais-Narkis model.

Table 1 Thermal properties of PC/EMA blends ${ }^{a}$

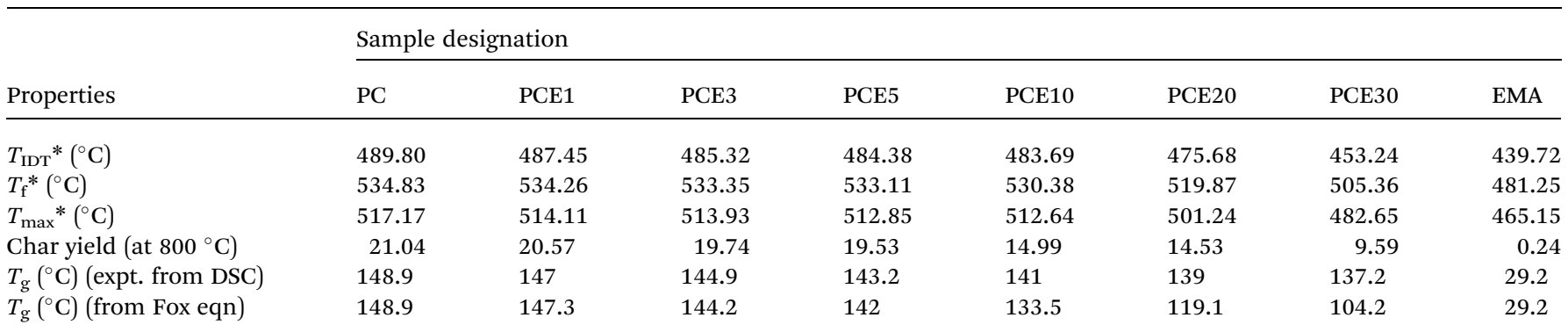

$a * T_{\mathrm{IDT}}$ - initial decomposition temperature, $T_{\mathrm{f}}$ - final decomposition temperature, $T_{\max }$ - temperature at which rate of mass loss is maximum obtained from DTG trace.

follows Fox equation and deviates to large extent in case of samples with higher \% EMA content.

Thermal characterization. Thermal stability of neat PC, EMA and PC/EMA blends was determined by recording TG/DTG traces in nitrogen atmosphere at a heating rate of $20{ }^{\circ} \mathrm{C}$ $\min ^{-1}$. Single step decomposition was observed in all the samples and the stability was compared by comparing initial decomposition temperature ( $\left.T_{\mathrm{IDT}}\right)$, decomposition temperature at which rate of weight loss was maximum $\left[T_{\max }\right.$ noted from DTG traces] and final decomposition temperature $\left[T_{\mathrm{f}}\right]$ (Fig. 7). $T_{\mathrm{IDT}}, T_{\mathrm{f}}$ and $T_{\max }$ decreased marginally upon incorporation of EMA but still all the samples were stable upto $450{ }^{\circ} \mathrm{C}$. Char yield of PC, EMA and PC/EMA blends was also noted from the TG traces and the results are summarized in Table 1. As expected, char yield decreased with increasing amounts of EMA in blend.
Fig. 8 shows the DSC second heating scans for neat PC, EMA and PC/EMA blends having varying amount of EMA. Second heating scans were used for the determination of glass transition temperature $\left(T_{\mathrm{g}}\right)$. In the DSC scans of all the samples, an endothermic shift in base line corresponding to $T_{\mathrm{g}}$ of PC was observed as shown in Fig.8. $T_{\mathrm{g}}$ was noted as a midpoint inflexion and the results are summarized in Table 1. A single $T_{\mathrm{g}}$ was observed and the $T_{\mathrm{g}}$ of PC decreased with increasing amounts of EMA. $T_{\mathrm{g}}$ of PC shifted to lower temperature and a decrease in $T_{\mathrm{g}}$ increased with an increase of EMA in blends. An attempt was also made to calculate $T_{\mathrm{g}}$ for blends using Fox equation (eqn (4)) and the results are given in Table 1 . Theoretical values agree well with the experimental values upto $\phi_{1}=$ 0.06 (5 wt $\%)$ whereas in case of samples having $\phi_{1}>0.06$, experimental values of $T_{\mathrm{g}}$ are higher than the theoretical values. 

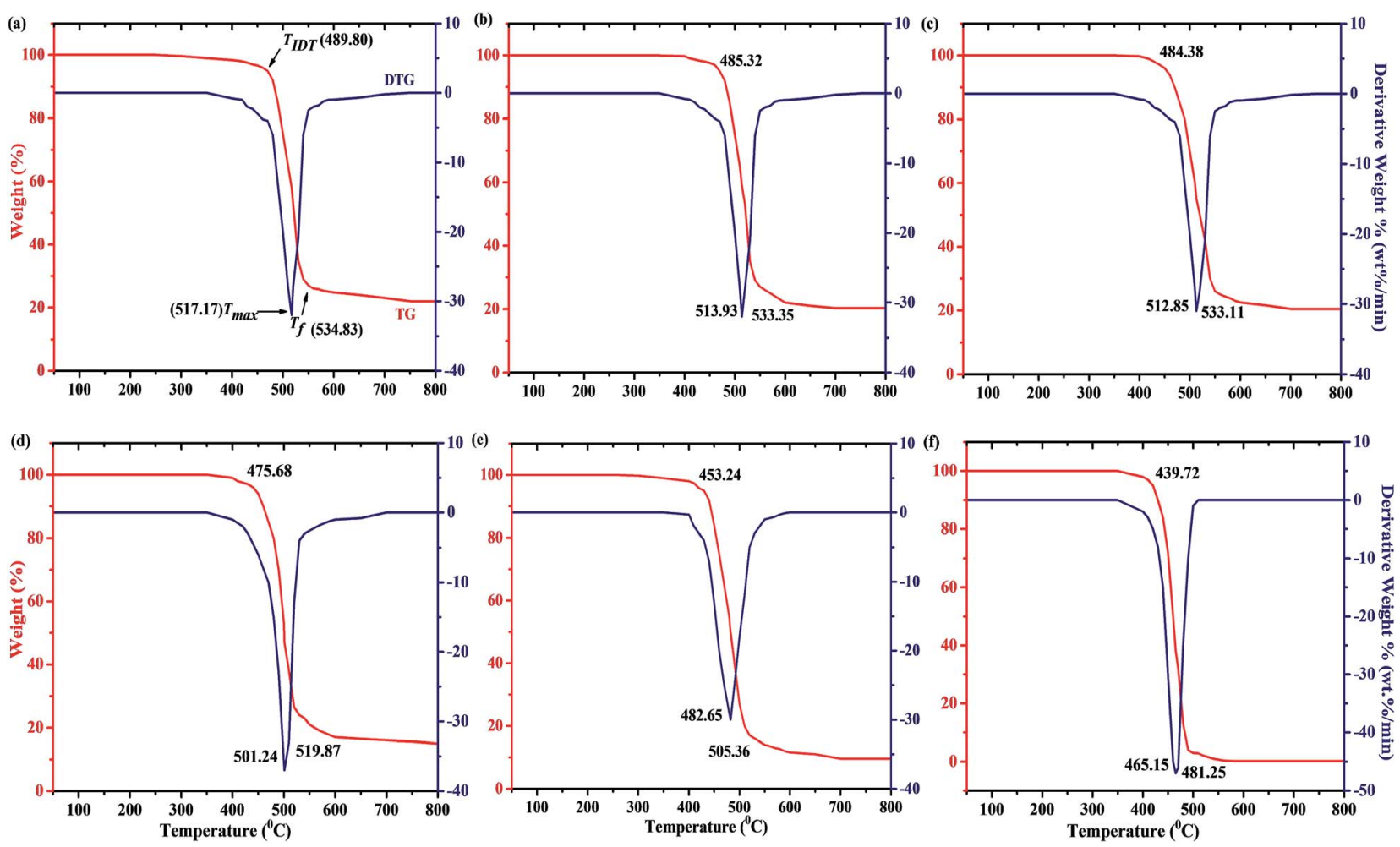

Fig. 7 (a-f): TG/DTG traces of: (a) PC; (b) PCE3; (c) PCE5; (d) PCE20; (e) PCE30; (f) EMA.

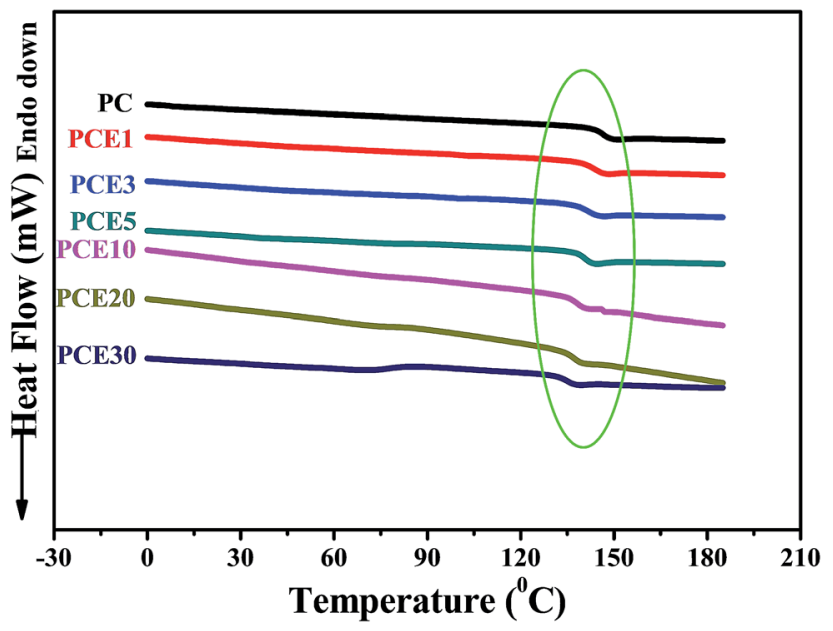

Fig. 8 DSC scan of PC and PC/EMA blends (heating scan).

This further supports that there is a good miscibility of rubber phase in PC matrix upto $\phi_{1}=0.06$ which was also established using Neilsen's first power-law model.

$$
\frac{1}{T_{\mathrm{gb}}}=\frac{w_{1}}{T_{\mathrm{g} 1}}+\frac{w_{2}}{T_{\mathrm{g} 2}}
$$

Where $T_{\mathrm{gb}}=$ glass transition temperature of blend, $T_{\mathrm{g} 1}=$ glass transition temperature of PC, $T_{\mathrm{g} 2}=$ glass transition temperature of EMA rubber, $w_{1}=$ weight fraction of $\mathrm{PC}, w_{2}=$ weight fraction of EMA rubber.

\section{Conclusion}

Incorporation of EMA rubber in PC matrix enhances the izod impact strength by $184-452 \%$. About 366 and $381 \%$ increase in impact strength of PC was observed upon incorporation of 3 and 5 wt $\%$ EMA rubber, respectively with slight decrease (6 and 10\% respectively) in tensile strength. Further increase in rubber content from $10-30$ wt $\%$ resulted in $389-452 \%$ increase in impact strength over that of neat PC but also decrease in tensile strength and tensile modulus by $23-52 \%$ and $23-38 \%$ respectively. The theoretical analysis of tensile properties shows that there is an extent of interaction between PC and EMA up to 5 wt $\%$ EMA content, whereas the interfacial adhesion deceased as EMA content was $>5$ wt $\%$. Scanning electron microscopy studies indicate a two-phase structure with fine globular rubber domains in the PC because of debonding of PC and EMA. At low EMA rubber content the two phase morphology is maintained and the globular size does not show appreciable change. At higher EMA rubber content the shape of the dispersed phase changes from spherical to elongated with enhanced particle size. This novel PC/EMA blends having significantly higher impact strength compared to PC can be used as an excellent impact absorber in various industries.

\section{References}

1 N. Katiyar and K. Balasubramanian, RSC Adv., 2014, 4, 47529-47535.

2 S. Pande, A. Chaudhary, D. Patel, B. P. Singh and R. B. Mathur, $R S C$ Adv., 2014, 4, 13839. 
3 Y. Guo, S. Sun and H. Zhang, RSC Adv., 2014, 4, 58880-58887. 4 A. S. Babal, R. Gupta, B. P. Singh, V. N. Singh, S. R. Dhakate and R. B. Mathur, RSC Adv., 2014, 4, 64649-64658.

5 A. S. Babal, R. Gupta, B. P. Singh and S. R. Dhakate, RSC Adv., 2015, 5, 43462-43472.

6 Y.-h. Wang, X.-l. Xu, J. Dai, J.-h. Yang, T. Huang, N. Zhang, Y. Wang, Z.-w. Zhou and J.-h. Zhang, RSC Adv., 2014, 4, 59194-59203.

7 J. B. Lee, Y. K. Lee, G. D. Choi, S. W. Na, T. S. Park and W. N. Kim, Polym. Degrad. Stab., 2011, 96, 553-560.

8 A. K. Bledzki, M. Rohleder, H. Kirschling and A. Chate, J. Cell. Plast., 2010, 46, 415-440.

9 K. Hareesh, P. Sen, R. Bhat, R. Bhargavi, G. G. Nair, Y. Sangappa and G. Sanjeev, Vacuum, 2013, 91, 1-6.

10 S. Pande, Processing and Properties of Carbon Nanotube/ Polycarbonate Composites, Scrivener Publishing LLC, 2014.

11 S. G. C. S. Singare, J. J. Zou and N. Li, Adv. Mater. Res., 2015, 1091, 63-69.

12 H. Kim and C. W. Macosko, Polymer, 2009, 50, 3797-3809.

13 B. P. Gearing and L. Anand, Int. J. Solids Struct., 2004, 41, 827-845.

14 R. Smit, W. Brekelmans and H. Meijer, J. Mater. Sci., 2000, 35, 2855-2867.

15 K. P. Chaudhari and D. D. Kale, Polym. Int., 2003, 52, 291298.

16 J. Wu, Y.-W. Mai and B. Cotterell, J. Mater. Sci., 1993, 28, 3373-3384.

17 F. Elmaghor, L. Zhang, R. Fan and H. Li, Polymer, 2004, 45, 6719-6724.

18 K. Cho, J. Yang, S. Yoon, M. Hwang and S. V. Nair, J. Appl. Polym. Sci., 2005, 95, 748-755.

19 C. Charitidis, A. Laskarakis, S. Kassavetis, C. Gravalidis and S. Logothetidis, Superlattices Microstruct., 2004, 36, 171-179.

20 I. González, P. Santamaría and J. I. Eguiazábal, Composites, Part A, 2015, 71, 227-234.

21 A. Rostami, M. Masoomi, M. J. Fayazi and M. Vahdati, $R S C$ Adv., 2015, 5, 32880-32890.

22 Y. Guo, J. He, X. Zhang, S. Sun and H. Zhang, J. Macromol. Sci., Part B: Phys., 2015, 54, 823-835.

23 N. A. Jamaludin, I. M. Inuwa, A. Hassan, N. Othman and M. Jawaid, J. Appl. Polym. Sci., 2015, 132, 42608.

24 Z. Tan, X. Xu, S. Sun and C. Zhou, Polym. Eng. Sci., 2006, 46, 1476.

25 M. Ishikawa, Polymer, 1995, 36, 2203-2210.

26 S. Tjong and Y. Meng, Eur. Polym. J., 2000, 36, 123-129.
27 Z.-M. Li, W. Yang, S. Yang, R. Huang and M.-B. Yang, J. Mater. Sci., 2004, 39, 413-431.

28 J. Wu, P. Xue and Y. W. Mai, Polym. Eng. Sci., 2000, 40, 786797.

29 X. Zhi, H.-B. Zhang, Y.-F. Liao, Q.-H. Hu, C.-X. Gui and Z.-Z. Yu, Carbon, 2015, 82, 195-204.

30 G.-P. Lin, L. Lin, X.-L. Wang, L. Chen and Y.-Z. Wang, Ind. Eng. Chem. Res., 2015, 54, 1282-1291.

31 R. Greco and A. Sorrentino, Adv. Polym. Technol., 1994, 13, 249-258.

32 Z.-M. Li, Z.-Q. Qian, M.-B. Yang, W. Yang, B.-H. Xie and R. Huang, Polymer, 2005, 46, 10466-10477.

33 Z. L. Liao and F. C. Chang, J. Appl. Polym. Sci., 1994, 52, 11151127.

34 R. Wiwattananukul, Y. Hachiya, S. Nobukawa and M. Yamaguchi, Polym. Compos., 2015, DOI: 10.1002/ pc. 23672 .

35 A. A. Ramteke and S. N. Maiti, J. Appl. Polym. Sci., 2010, 116, 486-492.

36 S. Kumar and S. N. Maiti, Polym.-Plast. Technol. Eng., 2007, 46, 427-433.

37 S.-m. Zhang, H.-x. Zhang, W.-y. Zhang, Z.-q. Wu and F. Chen, Chin. J. Polym. Sci., 2014, 32, 823-833.

38 V. Ramesh, M. Biswal, S. Mohanty and S. K. Nayak, Waste Manage. Res., 2014, 32, 379-388.

39 A. Farzadfar, S. N. Khorasani and S. Khalili, Polym. Int., 2014, 63, 145-150.

40 S. Balakrishnan and N. Neelakantan, Polym. Int., 1998, 45, 347-352.

41 Y. Liu, H. Li, X. Ding, J. Zhu, L. Zhang, W. Pan and R. Cai, American Journal of Materials Research, 2014, 1, 48-52.

42 M. Tașdemir, J. Appl. Polym. Sci., 2004, 93, 2521-2527.

43 T. Kunori and P. Geil, J. Macromol. Sci., Part B: Phys., 1980, 18, 135-175.

44 D. S. Parker, H.-J. Sue, J. Huang and A. F. Yee, Polymer, 1990, 31, 2267-2277.

45 M. Ishikawa and I. Chiba, Polymer, 1990, 31, 1232-1238.

46 A. Gupta and S. Purwar, J. Appl. Polym. Sci., 1984, 29, 35133531.

47 S. Maiti and B. Lopez, J. Appl. Polym. Sci., 1992, 44, 353-360. 48 S. Maiti and K. Sharma, J. Mater. Sci., 1992, 27, 4605-4613. 49 A. R. Bhattacharyya, S. Maiti and A. Misra, J. Appl. Polym. Sci., 2002, 85, 1593-1606.

50 L. E. Nielsen, J. Appl. Polym. Sci., 1966, 10, 97-103.

51 L. Nicolais and M. Narkis, Polym. Eng. Sci., 1971, 11, 194-199. 